\title{
CORPORATE SOCIAL RESPONSIBILITY, KEARIFAN LOKAL 'TRI HITA KARANA', DAN PARIWISATA BERBASIS MASYARAKAT BERKELANJUTAN
}

\author{
Luh Putu Mahyuni' ${ }^{1}$ I Gusti Ayu Agung Tistha Dewi \\ Fakultas Ekonomi dan Bisnis, Universitas Pendidikan Nasional \\ Jalan Bedugul No. 39, Sidakarya, Denpasar Selatan, Bali, Indonesia \\ E-mail : mahyuniluhputu@undiknas.ac.id \\ diterima: 3/7/2018; direvisi: 12/9/2018; diterbitkan: 26/9/2020
}

\begin{abstract}
This study explores how Corporate Social Responsibility (CSR) based on local wisdom 'tri hita karana' are implemented to develop a sustainable community-based tourism. This study uses a qualitative case study approach conducted at Sangeh Monkey Forest (MF) tourism object. Data were obtained through in-depth interviews and then analyzed by using coding and themeing technique. This research indicates that Sangeh MF tourism object implemented CSR in three major areas, namely: 1. Social (people and 'pawongan' in 'tri hita karana'); 2. Environment (planet and 'palemahan' in 'tri hita karana'); 3. CSR related to business operation and religious activities (profit and 'parahyangan' in 'tri hita karana'). CSR based on 'tri hita karana' principles were also implemented through participation of local community in managing the tourism object. All income generated from the operational of tourism object were given back to the community. The informant of this study perceived CSR as socially responsible business practices and as philanthropic actions. This research offers an insight into how CSR could be implemented based on local wisdom 'tri hita karana' to develop a sustainable community-based tourism object. Several recommendations on how to further improve CSR practices by integrating business, social, and environment goals are also offered.
\end{abstract}

Keywords: Corporate Social Responsibility, Local Wisdom Tri Hita Karana, Sustainable Community-Based Tourism

\section{PENDAHULUAN}

Pariwisata merupakan sektor yang membangun dan meningkatkan perekonomian di Indonesia. Setiap daerah memiliki pariwisata yang beragam baik wisata budaya, alam, sejarah, religi dan ekowisata. Pariwisata diharapkan dapat menciptakan lapangan pekerjaan agar dapat memeratakan pendapatan masyarakat. Namun, meningkatnya sektor perekonomian yang terjadi akibat adanya peningkatan pada perjalanan wisata dan aktivitas kepariwisataan di obyek wisata yang ada di Indonesia pada saat ini hanya dirasakan oleh para pengusaha atau para pelaku industri kepariwisataan. Masyarakat asli kebanyakan menjadi penonton saja dan jarang yang mendapat manfaat dari hasil wisata. Ini memicu konflik secara horisontal di tengah masyarakat (Komasary 2015). Para stakeholder pariwisata dengan manfaat yang diperoleh melalui kunjungan wisatawan memegang peranan penting dalam mengelola dampak positif maupun negatif yang ditimbulkan oleh aktivitas wisata.

Corporate Social Responsibility (CSR) merupakan upaya agar perusahaan tak hanya beroperasi untuk kepentingan shareholder, melainkan juga untuk kesejahteraan stakeholder dalam praktik bisnis, yaitu para pekerja, komunitas lokal, pemerintah, konsumen, dan lingkungan (Ernawan, Manajemen, and Pasundan 2016). Konsep CSR menekankan pada dua unsur, yaitu keharmonisan hubungan antara perusahaan dengan masyarakat serta keharmonisan hubungan perusahaan dengan lingkungan (Purwati and Tenaya 2018). Hal ini selaras dengan prinsip "tri hita karana', sebagai kearifan lokal Bali, 
Jurnal Ilmiah Ekonomi dan Bisnís

Vol. 17. No.2, September 2020 : 99-105

EISSN : $2442-9813$

ISSN : $1829-9822$

yang menyarankan pentingnya menjaga harmoni dengan Sang Pencipta ('parahyangan'), dengan sesama manusia ('pawongan') dan dengan lingkungan alam ('palemahan') (Purwati and Tenaya 2018).

Industri pariwisata menjadi salah satu sumber pendapatan terbesar dan menjadi salah satu sektor yang dapat mengembangkan perekonomian masyarakat Bali (Soritua 2016). Salah satu kabupaten/kota di Bali, yaitu Kabupaten Badung, memiliki berbagai macam destinasi wisata, salah satunya Sangeh Monkey Forest (MF) yang terletak di Desa Sangeh, Kecamatan Abiansemal, Badung. Desa Adat memainkan peranan penting dalam upaya pengembangan daya tarik wisata Sangeh $M F$ (Edi Arsawan, Kariati, and Wirga 2016). Kunjungan wisatawan ke obyek wisata Sangeh $M F$ memberikan dampak positif untuk Desa Adat, antara lain berupa peningkatan pendapatan asli desa (Edi Arsawan, Kariati, and Wirga 2016). Masyarakat di sekitar obyek wisata juga merasakan dampak tersebut dimana sebagian besar pemuda desa bekerja di bidang pariwisata (Wisnawa, Wijayanti, and Jokosaharjo 2019). Perkembangan industri pariwisata pada daerah sekitar kawasan juga mengalami peningkatan dimana masyarakat lokal memanfaatkan peluang yang diciptakan dari adanya kunjungan wisatawan ke Sangeh $M F$ dengan membuka guest house, tempat makan dan toko-toko (Wisnawa, Wijayanti, and Jokosaharjo 2019).

Meskipun terdapat banyak dampak positif yang timbul dari adanya peningkatan kunjungan wisatawan ke obyek wisata Sangeh $M F$, tetapi banyak juga dampak negatif yang ditimbulkan, seperti kerusakan alam dan lingkungan dimana kawasan hijau yang berlokasi di sekitar kawasan wisata telah beralih fungsi menjadi lahan industri pariwisata (Edi Arsawan, Kariati, and Wirga 2016).
Padatnya lalu lintas yang tak jarang menyebabkan kemacetan dan menimbulkan polusi udara serta kondisi jalan yang sudah mulai berlubang mengingat banyaknya kendaraan yang masuk ke daerah Sangeh (Edi Arsawan, Kariati, and Wirga 2016).

Selain itu, pengembangan kawasan pariwisata tanpa melibatkan peran serta masyarakat sebagai pengelola disinyalir sebagai salah satu penyebab munculnya dominasi investor luar Bali dalam pengelolaan bisnis pariwisata di Bali. MacRae mengestimasikan kurang lebih $80-85 \%$ usaha pariwisata dikuasai investor asing dan luar Bali (MacRae 2016), selebihnya didominasi kalangan elit lokal (Hitchcock 2010). Relatif minimnya kepemilikan dan peranserta aktif masyarakat lokal dalam pengelolaan bersama usaha pariwisata berdampak pada rendahnya dampak langsung pariwisata yang dirasakan masyarakat lokal. Dalam kaitan ini, pengembangan pariwisata berbasis masyarakat sangatlah penting, begitupula dengan berbagai kajian pendukungnya.

Pengelola kawasan wisata memiliki peran sangat penting untuk memastikan kawasan wisata dapat memberi manfaat positif yang optimal bagi masyarakat lokal tanpa menimbulkan dampak negatif yang signifikan. CSR merupakan salah satu strategi yang dapat diterapkan untuk menjamin keberlanjutan usaha dalam jangka panjang, serta untuk memastikan suatu usaha dapat memberi dampak positif yang optimal bagi perusahaan, masyarakat sekitar, dan lingkungan alam (Juniari and Mahyuni. 2020; Mahyuni 2017).

Penelitian ini dilakukan untuk mengeksplorasi bagaimana pengelola suatu kawasan wisata dapat menerapkan prinsip-prinsip CSR dilandasi kearifan lokal Bali, 'tri hita karana', untuk memastikan manfaat pariwisata dapat dirasakan sebesar-besarnya oleh masyarakat sekitar sekaligus 
meminimalisir dampak negatif yang ditimbulkannya. Penelitian ini diharapkan dapat berkontribusi bagi literatur, khususnya terkait studi kasus penerapan CSR berbasis kearifan lokal suatu daerah. Temuan penelitian ini diharapkan pula dapat dijadikan bahan referensi bagi pengelola kawasan wisata untuk mengintegrasikan konsep CSR dalam desain pengembangan pariwisata berbasis masyarakat berkelanjutan.

\section{TINJAUAN PUSTAKA}

CSR merupakan bentuk tanggungjawab sosial perusahaan terhadap seluruh pemangku kepentingan yang bertujuan untuk menjaga hubungan perusahaan dengan aspek ekonomi dan lingkungan sehingga dapat menciptakan pembangunan yang berkelanjutan. Menurut Wibisono (2007) CSR dapat didefinisikan sebagai tanggungjawab perusahaan untuk berlaku etis, meminimalkan dampak negatif dan memaksimalkan dampak positif yang mencakup aspek ekonomi sosial dan lingkungan (triple bottom line) dalam rangka mencapai tujuan pembangunan berkelanjutan. Ranah tanggungjawab sosial (Corporate Social Responsibility) mengandung dimensi yang sangat luas dan kompleks. Di samping itu, CSR juga mengandung interprestasi yang sangat berbeda, terutama dikaitkan dengan kepentingan pemangku kepentingan (stakeholder). Karena itu dalam rangka memudahkan pemahaman dan penyederhanaan, banyak ahli mencoba menggaris bawahi pinsip dasar yang terkandung dalam tanggungjawab CSR, yaitu people, profit, planet, yang menekankan pentingnya menjaga keselarasan upaya mendapatkan profit/keuntungan, menjaga hubungan antar manusia/people, dan menjaga hubungan dengan alam/planet (Elkington 1999).

Beberapa penelitian mengungkap bahwa CSR pada industri perhotelan dan pariwisata di Bali diimplementasikan berdasarkan nilai kearifan lokal tri hita karana, sehingga mencapai keberhasilan yang cukup baik, terutama dalam hal upaya mendapatkan legitimasi dan dukungan penuh masyarakat sekitar (Nadiawati and I G.A.N. Budiasih 2021; Juniari and Mahyuni. 2020; Darsika and Mahyuni 2020)

Teori stakeholder muncul pada pertengahan tahun 1980-an. Yang melatar belakangi pendekatan stakeholder adalah keinginan untuk sistem kerja yang responsif terhadap masalah yang dihadapi para manajer saat itu yaitu perubahan lingkungan. Tujuan dari manajemen stakeholder adalah untuk merancang cara yang digunakan untuk mengorganisir berbagai kelompok dan relasi yang dihasilkan dengan cara yang terstruktur. Menurut Hidayah et al (2019) Stakeholder adalah setiap kelompok atau individu yang dapat mempengaruhi atau dipengaruhi oleh pencapaian tujuan organisasi. Stakeholder dapat dibagi menjadi dua berdasarkan karakteristiknya yaitu stakeholder primer dan stakeholder sekunder. Stakeholder primer adalah kelompok investor, karyawan, konsumen dan pemasok, dimana apabila kelompok tersebut tidak ada, maka perusahaan tidak dapat bertahan untuk going concern. Sedangkan, yang termasuk ke dalam stakeholder sekunder yaitu pemerintah dan komunitas. Kelompok stakeholder sekunder yaitu mereka yang mempengaruhi atau dipengaruhi perusahaan, akan tetapi mereka tidak berhubungan dengan transaksi perusahaan (Salsabila and Santoso 2018). Stakeholder pada dasarnya dapat mengendalikan atau memiliki kemampuan untuk mempengaruhi pemakaian sumber-sumber ekonomi yang digunakan perusahaan. Oleh karena itu power stakeholder ditentukan oleh besar kecilnya power yang dimiliki stakeholder atas sumber tersebut (Fahrizqi 2010). 
Jurnal Ilmiah Ekonomi dan Bisnis

Vol. 17. No.2, September 2020 : 99-105

EISSN : $2442-9813$

ISSN : $1829-9822$

Pariwisata

(sustainable tourism) merupakan pariwisata yang berkembang pesat, termasuk pertambahan arus kapasitas akomodasi, populasi lokal dan lingkungan, dimana perkembangan pariwisata dan investasi - investasi baru dalam sektor pariwisata seharusnya tidak membawa dampak buruk dan dapat menyatu dengan lingkungan. Menurut Sukma (2014), pembangunan pariwisata berkelanjutan berkaitan dengan usaha untuk menjamin sumber daya alam, sosial dan budaya yang dimanfaatkan untuk pembangunan pariwisata pada generasi ini dapat dinikmati untuk generasi yang akan datang. Secara tidak langsung pariwisata berlandaskan masyarakat yang berkelanjutan dapat juga diartikan bagaimana masyarakat itu sendiri menjaga tatanan pariwisata yang dikelola dengan tetap mempertahankan asas ketahanan dan ketersediaan sumber daya alam.

Konsep pariwisata berbasis masyarakat berkelanjutan selaras dengan konsep CSR, yang berupaya membangun keselarasan antara tujuan peningkatan taraf perekonomian, kesejahteraan masyarakat, dan kelestarian lingkungan (Pribadi, Suganda, and Saefullah 2021; Juniari and Mahyuni. 2020).

\section{METODE PENELITIAN}

Penelitian ini dilakukan di kawasan wisata Sangeh Monkey Forest yang terletak di Desa Sangeh, Kecamatan Abiansemal, Kabupaten Badung. Lokasi penelitian dipilih berdasarkan beberapa pertimbangan: 1 . Kawasan pariwisata Sangeh merupakan salah satu kawasan wisata alam di Bali, dengan ikonnya berupa komunitas kera dalam hutan purba; 2. Merupakan cagar alam kawasan hutan tropis; 3. Masyarakat sekitar banyak menggantungkan hidup pada kawasan wisata Sangeh; 4. Kawasan obyek wisata Sangeh MF MF menjadi spot foto favorit untuk prawedding. Adapun metode penelitian yang digunakan dalam penelitian ini yaitu pendekatan kualitatif melalui wawancara secara mendalam atau in-depth interview. Informan penelitian dipilih secara purposive, dengan kriteria merupakan orang yang memahami dengan baik isu penelitian. Informan penelitian ini adalah kepala desa dinas, kepala/bendesa desa adat, pengelola obyek wisata, dan masyarakat lokal. Wawancara rata-rata berlangsung selama 60 menit dan direkam atas seijin informan. Rekaman wawancara kemudian diubah dalam bentuk transkrip untuk kemudian dianalisis dengan teknik coding dan themeing, yaitu suatu upaya peringkasan, katagorisasi, dan strukturisasi data (Saldana 2013). Untuk mempermudah proses analisis, pemaparan data, dan pembahasan, informan penelitian ini diberi kode I1 sampai dengan I4.

\section{HASIL DAN PEMBAHASAN}

Secara umum penelitian ini mengidentifikasikan enam tema utama beserta kode/sub temanya, yaitu: 1 . Persepsi atas CSR; 2. Persepsi atas pariwisata berbasis masyarakat; 3 . Implementasi prinsip-prinsip CSR dan 'tri hita karana'; 4. CSR dan pariwisata berbasis masyarakat berkelanjutan; 5 . Penganggaran praktik CSR; dan 6. Pengungkapan praktik CSR. Penjelasan lebih detail dipaparkan dalam uraian berikut.

\section{Persepsi Atas Corporate Social Responsibility (CSR)}

Beberapa penelitian terdahulu (Muhammad, Raharjo, and Resnawaty 2019; Santoso 2016; Sudarwati 2019) telah menunjukkan bahwa konsep CSR tidak cukup hanya dijelaskan dengan menggunakan tiga dimensi awal (people, profit, planet) saja, tetapi seiring berjalannya waktu tentu ada perkembangan. Beberapa penelitian menggunakan konsep sustainable 
development yang menjelaskan bahwa masyarakat mampu membedakan tiga dimensi konstruk CSR yaitu ekonomi, sosial dan lingkungan (Siwi 2017). Implementasi CSR yang baik diharapkan dapat memberikan keuntungan bagi stakeholder pariwisata, yaitu pengunjung, pengelola dan masyarakat lokal.

Informan penelitian ini memahami CSR sebagai wujud praktik bisnis yang bertanggungjawab secara sosial (socially responsible business practices) sekaligus sebagai wujud kepedulian kepada mereka yang kurang mampu (corporate philanthrophy). Informan I2 menyatakan, "CSR adalah tanggungjawab sosial suatu perusahaan kepada masyarakat sekitar perusahaan. Salah satu bentuknya melalui upaya pemberdayaan masyarakat sekitar perusahaan" (I2). Hal tersebut sesuai dengan kategori CSR sebagai Socially Responsible Business Pratices, yaitu praktik bisnis bertanggungjawab, yang peduli atas kesejahteraan masyarakat di sekitar perusahaan (Rahmadani, Raharjo, and Resnawaty 2019). Temuan penelitian ini sejalan dengan pendapat Suib \& Faizah (2019) yang menyatakan bahwa "CSR adalah komitmen perusahaan dalam menjalankan bisnis dengan tetap memperhatikan lingkungan sekitar....Selain itu, pelaksanaan CSR juga memberi manfaat bagi perusahaan dan masyarakat. Bagi masyarakat, dengan adanya CSR dapat meningkatkan kesejahteraan, sedangkan bagi perusahaan akan meningkatkan citra baik di mata masyarakat". Penelitian oleh Darsika dan Mahyuni (2020) juga menemukan persepsi CSR sebagai praktik bisnis yang bertanggungjawab secara sosial kepada masyarakat sekitar.

Informan lain penelitian ini mempersepsikan CSR sebagai aktivitas philanthropy semata. Sebagaimana dinyatakan I1, "CSR adalah kegiatan pemberian bantuan sosial seperti dana sosial serta sembako" (I1). Pernyataan I1 juga didukung oleh I3 yang menyebutkan bahwa, "CSR adalah bantuan sosial" (I3). Penjelasan informan tersebut sesuai dengan kategori CSR sebagai Corporate Philanthropy, yaitu kontribusi langsung perusahaan kepada masyarakat dengan pemberian sumbangan dalam bentuk uang tunai, paket bantuan, pemberian beasiswa atau pelayanan secara cuma-cuma (Aqiela, Raharjo, and Resnawaty 2019). Temuan penelitian ini senada dengan beberapa studi sebelumnya (Dianti and Mahyuni 2018; Juniari and Mahyuni. 2020) yang mengindikasikan bahwa CSR hanya dipahami sebatas sebagai aktivitas philanthrophy.

Porter dan Kramer (Porter and Kramer 2002, 2006) menyarankan, untuk dampak yang lebih optimal baik bagi perusahaan maupun bagi masyarakat sekitar, CSR perlu dipahami sebagai bagian integral dari strategi perusahaan, tidak sekedar sebagai aktivitas philanthrophy saja, yang tidak ada kaitannya secara langsung dengan operasional perusahaan.

\section{Persepsi Atas Pariwisata Berbasis Masyarakat}

Seiring berjalannya waktu, program CSR tidak hanya dijadikan sebagai upaya perusahaan untuk menunjukkan rasa kepedulian terhadap perkara sosial dan lingkungan tetapi juga dijadikan sebagai pendukung agar dapat terwujudnya pembangunan yang berkelanjutan dengan menyeimbangkan aspek ekonomi dan pembangunan sosial yang didukung dengan perlindungan terhadap lingkungan hidup (Maulidiana, 2018). Suriany (2013) mengatakan bahwa Community Based Tourism (CBT) adalah bentuk pariwisata yang memberikan kesempatan kepada masyarakat lokal untuk mengontrol dan terlibat dalam manajemen dan pembangunan pariwisata, agar masyarakat juga mendapat keuntungan dari pariwisata tersebut. 
Jurnal Ilmiah Ekonomi dan Bisnís

Vol. 17. No.2, September 2020 : 99-105

EISSN : $2442-9813$

ISSN : $1829-9822$

Dalam mengembangkan suatu daya tarik wisata, partisipasi atau keterlibatan masyarakat lokal tidak bisa diabaikan begitu saja. Masyarakat lokal merupakan orang pertama yang mengetahui kondisi daerahnya daripada orang yang berasal dari luar daerah. Dengan demikian, partisipasi masyarakat lokal sangat diperlukan baik dalam perencanaan, pelaksanaan, pengembangan hingga akhir, yaitu evaluasi kerja (Ratnaningsih 2014). Harapan kedepannya ialah tiada lain untuk mewujudkan sikap rasa memiliki pada diri masyarakat lokal sendiri, sehingga timbul kesadaran dan tanggung jawab untuk ikut serta dalam mengembangkan daya tarik wisata.

Dari hasil wawancara mendalam, penelitian ini menemukan indikasi kesesuaian persepsi informan dengan definisi pariwisata berbasis masyarakat yang diberikan oleh Sastrayuda (2010), "Pariwisata berbasis masyarakat adalah pariwisata dimana masyarakat memainkan peranan penting dan utama dalam pengembangan pariwisata". Informan penelitian ini mempersepsikan pariwisata berbasis masyarakat sebagai berikut, "Dengan adanya obyek wisata, ada pendapatan yang masuk ke desa, otomatis yang menjadi prioritas tentu masyarakat desa dimana obyek wisata Sangeh sudah menerapkan konsep ini dengan membuka lapangan pekerjaan serta peluang bisnis untuk masyarakat desa dan masyarakat sekitar obyek wisata Sangeh" (I2). Pernyataan senada juga diungkapkan oleh I1, "Semua yang terkait dengan pariwisata berupaya memaksimalkan peran serta aktif masyarakat atau bisa disebut swakelola" (I1). Lebih lanjut I3 menjelaskan, "Menurut saya, obyek wisata Sangeh telah menerapkan pariwisata berbasis masyarakat, karena seluruh pegawai dan pedagang yang ada disini diutamakan masyarakat lokal" (I3).

$$
\text { Menurut Adikampana (2017), }
$$

partisipasi masyarakat dapat dibagi menjadi 3 tingkatan dalam proses pembangunan pariwisata yaitu: (a) Pseudo Community Participation; tidak berpartisipasi, pembangunan pariwisata tujuannya tidak untuk pelibatan kolektif masyarakat, keputusan yang berhubungan dengan pemenuhan kebutuhan pokok guna meminimalkan resiko, kebijakan jangka pendek, top-down, tidak langsung, hanya melibatkan elit lokal, dominasi pemerintah. (b) Passive Community Participation; hanya sebagai endorsement atau ratifikasi keputusan yang dibuat untuk masyarakat, hanya terlibat dalam implementasi, minim kontribusi masyarakat, efektivitas dan efisiensi pencapaian tujuan pihak eksternal. (c) Spontaneous Community Participation; dimana masyarakat berpartisipasi langsung, partisipasi aktif dan partisipasi otentik.

Berdasarkan hasil wawancara mendalam, penelitian ini mengindikasikan bahwa persepsi informan atas pariwisata berbasis masyarakat yang diterapkan di obyek wisata Sangeh MF memenuhi kriteria partisipasi masyarakat berbentuk Spontaneous Community Participation atau partisipasi langsung dan aktif dari masyarakat lokal. Pada pengelolaan obyek wisata Sangeh MF, peranan dan partisipasi masyarakat lokal sangat diprioritaskan. Hal tersebut dapat diketahui dari pernyataan informan I1, I2, dan I3, yang menjelaskan antara lain bahwa karyawan yang bekerja di obyek wisata Sangeh MF hanya diperbolehkan dari masyarakat lokal saja.

Penelitian ini menemukan praktik Spontaneous Community Participation dalam pengelolaan obyek wisata Sangeh sebagaimana yang disarankan Jannah \& Suryasih (2019), “...dalam penerapan pariwisata berbasis masyarakat, komunitas lokal diharapkan dapat berpartisipasi secara langsung atau Spontaneous Community Participation dalam pembangunan dan pengembangan 
kepariwisataan di daerah masingmasing dan memberikan perhatian lebih terhadap sumber daya alam, seni, dan budaya yang mereka miliki disamping meningkatkan kesejahteraan sosial melalui manfaat ekonomi yang diperoleh".

Konsep Corporate Social Responsibility (CSR) menekankan pada dua unsur, yaitu keharmonisan hubungan antara perusahaan dengan masyarakat serta keharmonisan hubungan perusahaan dengan lingkungan. Berdasarkan hasil wawancara yang mendalam terungkap bahwa praktik CSR yang dilaksanakan oleh obyek wisata Sangeh MF telah sesuai dengan prinsip The Triple Botton Line dan 'tri hita karana', dimana dalam pelaksanaannya diwujudkan dengan program kerja pada bidang sosial dan bidang lingkungan. Berikut penjelasan lebih detail untuk setiap prinsip.

Prinsip ini diwujudkan pada program kerja di bidang sosial yang telah dilakukan oleh perusahaan dengan memberikan bantuan sosial kepada 'pemangku' (pemuka agama), kaum lanjut usia (lansia) dan difabel. Program ini dijalankan dengan memanfaatkan pendapatan yang diterima obyek wisata Sangeh MF. Pendapatan obyek wisata Sangeh MF didistribusikan secara adil dan proporsional. Persentase pembagian pendapatan untuk Desa Adat sebesar $75 \%$ dan untuk Pemerintah Daerah Badung sebesar 25\%. Pendapatan yang diterima desa adat digunakan untuk membiayai kegiatan pembangunan, baik berupa fasilitas umum maupun pura beserta upacara keagamaan. Selain itu, pendapatan yang diterima desa adat juga digunakan untuk melakukan pemeliharaan fasilitas umum yang dimiliki Desa Sangeh, seperti wantilan desa, gamelan milik desa, balai banjar dan sebagainya. Penjelasan terkait implementasi prinsip people dan 'pawongan' ini diberikan oleh informan
I1 dan I3.

ISSN : $1829-9822$

Prinsip ini diwujudkan pada program kerja di bidang lingkungan dengan melaksanakan penanaman pohon kembali dan perluasan hutan di obyek wisata Sangeh MF. Kegiatan yang dilakukan untuk melestarikan hutan dan keberadaan kera-kera antara lain: 1. Menanam hutan kembali seluas lebih dari empat hektar dengan tanaman yang beragam, seperti: albesia, mahoni, beringin, cempaka,kecik,sawo, gamal, waru,durian,gunggung dan jambu biji disebut hutan tambahan dari hutan inti seluas lebih dari sepuluh hektar yang terdiri dari tanaman sejenis, yaitu: pohon pala; 2. Pengelola dari Sangeh MF yang didampingi oleh Dinas Peternakan Kabupaten Badung secara rutin mengecek dan menjaga kesehatan kera-kera, serta memberikan makan dan minum dengan teratur setiap dua kali sehari kepada kerakera, yaitu pada pagi dan sore hari.

Obyek wisata Sangeh MF sangat memperhatikan dan mendukung pelaksanaan upacara keagamaan pada pura-pura yang berada dalam kawasan Desa Adat Sangeh, sebagai implementasi prinsip 'parahyangan'. Sebagaimana dinyatakan oleh I1, "Sетua keperluan upacara keagamaan di pura, dibiayai dari hasil pendapatan obyek wisata Sangeh, sehingga sangat meringankan beban masyarakat" (I1). Pernyataan ini diperkuat oleh pernyataan I2, "Pendapatan obyek wisata Sangeh selain diprioritaskan untuk meningkatkan kesejahteraan masyarakat juga untuk mendukung kegiatan keagamaan di pura" (I2). Informan penelitian ini meyakini upaya pengelola obyek wisata Sangeh untuk membiayai kegiatan keagamaan di pura-pura dalam kawasan Desa Adat Sangeh merupakan upaya untuk memohon berkah dari Yang Maha Kuasa dalam pengelolaan obyek wisata agar dapat tetap memberikan keuntungan/profit bagi masyarakat sekitar. Selain itu, kegiatan upacara keagamaan pada pura-pura dalam 


\section{Jurnal Ilmiah Ekonomi dan Bisnis}

Vol. 17. No.2, September 2020 : 99-105

EISSN : $2442-9813$

ISSN : 1829-9822

kawasan Desa Adat Sangeh, yang berlangsung hampir sepanjang tahun, dipercaya dapat menjadi salah satu daya tarik wisatawan untuk datang berkunjung. Hal ini tentu saja akan dapat meningkatkan pendapatan yang diperoleh obyek wisata Sangeh.

Temuan penelitian ini terkait implementasi prinsip-prinsip CSR dan 'tri hita karana' senada dengan penelitian Rosilawati \& Mulawarman (2019) yang menemukan adanya penerapan prinsip CSR berbasis 'tri hita karana' yang dapat menciptakan hubungan harmonis antara manusia dengan Tuhan ('parahyangan'), manusia dengan sesama manusia ('pawongan') dan manusia dengan alam lingkungan ('palemahan'). Penelitian ini mengindikasikan bahwa penerapan CSR berbasis 'tri hita karana' dapat memberikan dampak positif bagi peningkatan kesejahteraan masyarakat, pelestarian lingkungan serta memperkuat operasional bisnis tanpa meninggalkan nilai budaya. Selain itu, temuan penelitian ini juga mendukung penelitian Rita (2019) yang menyatakan bahwa CSR merupakan usaha perusahaan dalam menjalankan kegiatan bisnisnya secara lebih terintegrasi, antara tujuan perusahaan sebagai usaha bisnis dengan tujuan menjaga keharmonisan hubungan dengan masyarakat, alam, dan Tuhan.

Dalam teori stakeholder dijelaskan bahwa eksistensi suatu perusahaan memerlukan dukungan dari stakeholders, sehingga aktivitas perusahaan juga mempertimbangkan persetujuan dari stakeholders. Pelaksanaan CSR oleh obyek wisata Sangeh MF telah mengimplementasikan teori stakeholders dan konsep pariwisata berbasis masyarakat, dimana program CSR dibuat untuk kesejahteraan para stakeholders dan pengelolaannya dengan melibatkan masyarakat lokal. Obyek wisata Sangeh MF dikelola oleh masyarakat dan hasilnya dinikmati oleh masyarakat sendiri melalui programprogram yang telah direncanakan, sehingga dapat mewujudkan pembangunan pariwisata yang berkelanjutan. Berikut rangkuman hasil wawancara dan penjelasan lebih detail terkait kaitan CSR yang diterapkan obyek wisata Sangeh MF dengan pariwisata berbasis masyarakat, mengacu pada prinsip-prinsip pariwisata berkelanjutan yang disebutkan Arida (2017), yaitu: partisipasi; keikutsertaan para pelaku pariwisata; kepemilikan lokal; penggunaan sumber daya yang berkelanjutan; mewadahi tujuan-tujuan masyarakat; daya dukung; monitor dan evaluasi; akuntabilitas; pelatihan dan promosi.

Obyek wisata Sangeh MF telah menerapkan prinsip ini dimana masyarakat setempat telah ikut mengawasi atau mengontrol pembangunan pariwisata, sebagaimana dinyatakan informan I3, "Seluruh kegiatan pariwisata yang ada di sini dijalankan dan dikelola masyarakat lokal" (I3). Hal ini berarti dengan melibatkan masyarakat diharapkan dapat membantu pengembangan dan pengelolaan daya tarik wisata untuk mewujudkan pariwisata berbasis masyarakat yang berkelanjutan.

Berdasarkan hasil wawancara dan observasi, penelitian ini menemukan terdapatnya keikutsertaan para pelaku pariwisata yang terdiri dari komunitas lokal berbentuk Kelompok Sadar Wisata Bukit Sari Sangeh dan pengurus desa adat dalam mengelola obyek wisata Sangeh MF. Desa adat berperan dalam mengawasi perkembangan pengelolaan obyek wisata Sangeh MF.

Obyek wisata Sangeh MF telah menerapkan prinsip kepemilikan lokal sebagaimana penjelasan informan I1, "Hasil pengelolaan obyek wisata Sangeh sepenuhnya dinikmati dan dimiliki masyarakat lokal. Sarana dan prasana penunjang bagi penduduk lokal untuk 
berjualan pada obyek wisata Sangeh Monkey Forest juga dibangun dari hasil pengelolaan obyek wisata" (I1).

Obyek wisata Sangeh MF memanfaatkan sumber daya alam berupa hutan yang dihuni oleh kera-kera sebagai daya tarik wisata. Dalam menjaga kelestarian dari hutan pala Sangeh dan kera-keranya, desa adat beserta badan pengelola mewujudkan langkah-langkah nyata untuk melestarikan keberadaan kera-kera serta hutan pala tersebut dengan cara perluasan hutan serta pemberian makan secara teratur sebanyak dua kali sehari, pagi dan sore kepada kera-kera.

Pengelola obyek wisata Sangeh MF berupaya mewadahi tujuan-tujuan masyarakat dalam pengelolaannya, sebagaimana dijelaskan oleh I1, "Sudah pasti, karena seluruh program yang dibuat juga untuk kesejahteraan masyarakat dan keberlangsungan wisata yang ada" (I1) dan didukung oleh pernyataan I3, "Tentu saja, seluruh program yang dibuat juga untuk kesejahteraan masyarakat dan kami dari pengelola berharap bisa mewujudkan pariwisata berbasis masyarakat yang berkelanjutan" (I3).

Berdasarkan hasil wawancara dan observasi, pendapatan yang masuk pada obyek wisata Sangeh MF digunakan untuk melaksanakan dan membiayai setiap kegiatan pembangunan, baik fasilitas umum maupun pura-pura beserta upacara keagamaannya, sehingga dengan adanya kegiatan pariwisata hal ini dapat meringankan sedikit beban dari masyarakat Sangeh.

Dalam pelaksanaan aktivitas wisata di obyek wisata Sangeh MF, desa adat berperan untuk mengawasi dan mengevaluasi perkembangan pengelolaan obyek wisata Sangeh MF. Desa adat secara rutin melakukan pengawasan dengan melihat secara langsung kegiatan dan interaksi yang terjadi pada obyek wisata Sangeh MF.
Menerima saran-saran dari badan pengelola berkaitan dengan kenyamanan wisatawan, fasilitas wisata serta menerima pula keluhan-keluhan dari wisatawan. Selanjutnya, pemerintah desa mengadakan pertemuan secara umum yang melibatkan tokoh-tokoh desa untuk mendapatkan saran serta solusi untuk penyelesaian masalah yang ditemui dalam pengelolaan obyek wisata Sangeh MF.

Prinsip akuntabilitas diterapkan oleh pengelola obyek wisata Sangeh MF dengan mengalokasikan pendapatan yang diterima untuk bantuan sosial, pembangunan dan pemeliharaan pura dan fasilitas desa serta membiayai upacara keagamaan yang berlangsung di Desa Sangeh.

Pengelola obyek wisata Sangeh MF secara rutin mengadakan kegiatan pelatihan yang berkaitan dengan kepariwisataan bagi pengelola maupun karyawan, untuk meningkatkan kualitas pelayanan kepada wisatawan.

Pengelola obyek wisata Sangeh MF melakukan kegiatan promosi melalui kerjasama dengan travel agent serta mempromosikan obyek wisata melalui website dan media sosial yang dimiliki. Untuk menambah daya tarik wisata, pengelola membangun beberapa jalur tracking yang memungkinkan wisatawan menikmati keindahan hutan alam obyek wisata Sangeh MF dari berbagai sisi dan secara lebih dekat.

Dalam pelaksanaan CSR, pengalokasian dana CSR oleh perusahaan perlu memperhatikan beberapa hal seperti apakah dana tersebut sudah dialokasikan dengan tepat, apakah besaran anggarannya sesuai dengan program yang akan dijalankan, dan bagaimana dampak atau manfaat yang akan diterima dari penganggaran pelaksanaan CSR tersebut. Keberhasilan berjalannya program CSR seringkali tidak ditentukan semata oleh besar kecilnya anggaran untuk program CSR, melainkan juga ditentukan oleh efektivitas proses perencanaan, 
Jurnal Ilmiah Ekonomi dan Bisnís

Vol. 17. No.2, September 2020 : 99-105

EISSN : $2442-9813$

ISSN : $1829-9822$

penganggaran CSR, pelaksanaan, dan pengawasan (Ratnaningsih 2014).

Berdasarkan hasil wawancara, pengelola obyek wisata Sangeh MF telah melakukan penganggaran untuk setiap program CSR, sebagaimana dinyatakan oleh I2, "Kegiatan CSR dianggarkan sesuai persentase tertentu dari keuntungan yang masuk" (I2) dan I1 yang mengatakan "Program CSR dianggarkan setiap tahunnya dari keuntungan obyek wisata Sangeh MF agar lebih efektif pelaksanaannya" (I1).

Temuan penelitian ini mengindikasikan bahwa proses penganggaran diperlukan untuk memastikan pelaksanaan CSR berjalan efektif. Hal ini selaras dengan temuan penelitian Dianti \& Mahyuni (2018), dimana penyusunan anggaran merupakan hal penting bagi perusahaan untuk membantu pelaksana dalam merencanakan kegiatan dan memberikan gambaran awal seberapa besar dana yang akan dikeluarkan untuk mewujudkan kegiatan tersebut, sehingga berbagai potensi penyimpangan dapat diminimalisasi.

Menurut Sri Rokhlinasari (2012), teori stakeholder menjelaskan bahwa eksistensi perusahaan memerlukan dukungan dari stakeholder, sehingga aktivitas perusahaan juga perlu mempertimbangkan persetujuan dari stakeholder. Pengungkapan CSR, menurut teori stakeholder, dirancang untuk menjaga keberlangsungan hubungan yang terjadi antara perusahaan dengan stakeholdernya, untuk membangun citra positif di mata masyarakat dan untuk meningkatkan kepercayaan masyarakat terhadap perusahaan.

Berdasarkan hasil wawancara yang dilakukan, terungkap bahwa praktik CSR beserta besaran dana yang dikeluarkan untuk mendanai CSR tidak dilaporkan kepada masyarakat umum, melainkan hanya dilaporkan di hadapan pengelola desa adat sebagai pelaksana fungsi pengawasan. Sebagaimana dijelaskan oleh I2, "Untuk pelaporan setiap bulan kami buat yang kemudian akan ada tim 'panureksa' (pengawas) desa yang akan memeriksa" (I2) dan I1, "Laporan yang kami buat, setelah diperiksa kemudian oleh pemerintahan desa dibuatkan laporan tahunan untuk disampaikan kepada pemerintah daerah" (I1).

Penelitian ini mengungkapkan bahwa pengelola obyek wisata Sangeh MF menerapkan prinsip transparansi dan akuntabilitas dengan menyusun dan melaporkan pengelolaan dana obyek wisata, termasuk pengeluaran untuk program CSR kepada pihak pengawas desa. Hal ini mendukung penelitian Pasttisahusiwa \& Diyanti (2017) yang menyatakan bahwa pengungkapan praktik CSR merupakan wujud transparansi dan tanggung jawab atau komitmen yang dilakukan perusahaan atas dampak yang ditimbulkan oleh aktivitas bisnisnya.

Cukup banyak penelitian yang telah dilakukan untuk mengkaji implementasi CSR, bagaimana CSR diimplementasikan berdasarkan nilai-nilai kearifan lokal, maupun implementasi pariwisata berbasis masyarakat berkelanjutan, namun kajiankajian tersebut masih dilakukan secara terpisah. Penelitian ini menawarkan kebaruan dalam hal upaya mengkaji secara komprehensif bagaimana CSR berbasis kearifan lokal diimplementasikan pada konteks pengembangan pariwisata berbasis masyarakat berkelanjutan. Temuan penelitian ini dapat digunakan sebagai panduan untuk mengintegrasikan CSR ke dalam desain pembangunan pariwisata berbasis masyarakat berkelanjutan. 


\section{KESIMPULAN DAN SARAN}

Melalui wawancara mendalam dengan kepala desa dinas, kepala/bendesa desa adat, pengelola obyek wisata, dan masyarakat lokal obyek wisata Sangeh MF, penelitian ini menemukan bahwa prinsip CSR dan kearifan lokal 'tri hita karana' diterapkan untuk mewujudkan pariwisata berbasis masyarakat berkelanjutan. Secara umum terdapat tiga jenis praktik CSR yang dilakukan: (1) Pada bidang sosial, dengan mengimplementasikan prinsip people pada the triple bottom line dan 'pawongan' pada 'tri hita karana', pengelola obyek wisata memberikan berbagai bantuan sosial kepada pemuka agama, orang lanjut usia, dan penyandang disabilitas. (2) Pada bidang lingkungan, dengan mengimplementasikan prinsip planet pada the triple bottom line dan 'palemahan' pada 'tri hita karana', pengelola obyek wisata melakukan penanaman pohon kembali dan perluasan hutan pada obyek wisata Sangeh MF. (3) Dengan mengimplementasikan prinsip profit pada the triple bottom line dan 'parahyangan' pada 'tri hita karana', pengelola obyek wisata membantu penuh pembangunan maupun pemugaran pura dan pembiayaan upacara keagamaan. Selain untuk memohon berkah Yang Maha Kuasa, diharapkan pula pelaksanaan upacara keagamaan yang berlangsung hampir sepanjang tahun dapat menjadi daya tarik wisatawan, sehingga dapat meningkatkan profit.

Penelitian ini juga menemukan bahwa pengelola obyek wisata Sangeh MF melakukan penganggaran untuk program-program CSR dan melaporkan pelaksanaan CSR dalam satu kesatuan laporan keuangan kepada pengawas desa, setiap bulannya. Praktik CSR yang dilakukan tidak dilaporkan secara meluas kepada masyarakat umum, melainkan dilaporkan pada pihak-pihak tertentu saja dan secara tertutup, yakni kepada pengelola desa dan kabupaten.
Adapun saran yang dapat diberikan kepada pengelola obyek wisata Sangeh MF, maupun pengelola obyek wisata alam sejenis antara lain: (1) Mengembangkan lebih banyak lagi program CSR yang tidak sebatas kegiatan philanthropy, melainkan program yang dapat mendukung keberlangsungan usaha obyek wisata Sangeh MF, misalnya melibatkan wisatawan dalam kegiatan penanaman pohon sebagai satu paket wisata alam, membantu petani lokal mengembangkan komoditas pertanian khas daerah Sangeh yang dapat ditawarkan pada obyek wisata, seperti buah manggis. (2) Praktik CSR yang telah dilaksanakan agar dapat dipublikasi secara digital pada website resmi obyek wisata Sangeh MF maupun website resmi Desa Adat Sangeh agar masyarakat lokal maupun umum dapat mengetahuinya. Selain itu, pengungkapan praktik CSR secara meluas juga dipercaya dapat membantu meningkatkan citra dan promosi obyek wisata.

Sekalipun penelitian ini dilakukan pada obyek wisata Sangeh MF, di Bali, temuan penelitian ini mungkin saja relevan dan berguna pada konteks wisata alam sejenis. Penelitian berikutnya dapat menggali lebih jauh mengenai dampak penerapan CSR berbasis kearifan lokal bagi pengelolaan obyek wisata alam, yang belum tereksplorasi maksimal dalam penelitian ini

\section{DAFTAR PUSTAKA}

Adikampana, I Made. 2017. Pariwisata Berbasis Masyarakat.

Aqiela, Lin, Santoso Tri Raharjo, and Risna Resnawaty. 2019. "Implementasi Program Corporate Social Responsibility (Csr) El-Corps." Share: Social Work Journal 8 (2): 211.

https://doi.org/10.24198/share.v8i2.20 082.

Arida, Nyoman Sunarta Nyoman Sukma. 2017. Pariwisata Berkelanjutan. Cakra Press.

Darsika, A A Made Pradnya, and Luh Putu 
Jurnal Ilmiah Ekonomi dan Bisnis

Vol. 17. No.2, September 2020 : 99-105

EISSN : $2442-9813$

ISSN : $1829-9822$

Mahyuni. 2020. "Corporate Social

Responsibility: Eksplorasi Persepsi,

Motivasi Dan Praktik." E-Jurnal

Ekonomi Dan Bisnis Universitas

Udayana 9 (8): 687-708.

https://doi.org/10.24843/eeb.2020.v0

9.i08.p01.

Dianti, Gina Putri, and Luh Putu Mahyuni. 2018. "Praktik Corporate Social Responsibility ( CSR ) Pada Interkontinental Bali Resort Hotel: Eksplorasi Berbasis Tri Hita Karana." Jurnal Ilmiah Akuntansi Dan Bisnis 3 (1): 12-22.

Edi Arsawan, I Wayan, Ni Made Kariati, and I Wayan Wirga. 2016. "Strategi Revitalisasi Kawasan Wisata Sangeh." Jurnal Sosial Dan Humaniora 6 (3): 169-84.

Elkington, John. 1999. Cannibals With Fork: Triple Bottom Line of 21st Century Business. Oxford: United Kingdom: John Wiley \& Sons, Ltd.

Ernawan, Erni R, Program Studi Manajemen, and Universitas Pasundan. 2016. "Tanggungjawab Sosial Perusahaan (Corporate Social Responsibility) Dalam Perspektif Kebijakan Pembangunan Pertanian." Analisis Kebijakan Pertanian 6 (2): 155-73.

https://doi.org/10.21082/akp.v6n2.20 08.155-173.

Fahrizqi, Anggara. 2010. "Faktor-Faktor Yang Mempengaruhi Luas Pengungkapan Corporate Social Responsibility (Csr) Dalam Laporan Tahunan Perusahaan." Disability and Rehabilitation 20 (1): 87-108.

Hidayah, Ni A, Simon S Hutagalung, Dedy Hermawan, Fakultas Ilmu, Universitas Lampung, Diterima Februari, Disetujui April, Dipublikasikan Juni, and Kabupaten Pringsewu. 2019. "Analisis Peran Stakeholder Dalam Pengembangan Wisata Talang Air Peninggalan Kolonial Belanda Di Kelurahan Pajaresuk Kabupaten Pringsewu
Peran Stakeholder Dibutuhkan Untuk Mengoptimalkan Pelaksanaan Pembangunan Termasuk Pembangun." Jurnal Administrasi Publik 7: 55-71.

Hitchcock, Michael. 2010. "Tourism and Total Crisis in Indonesia: The Case of Bali." Asia Pacific Business Review 8 (2).

Jannah, Haniva Rohmatul, and Ida Ayu Suryasih. 2019. "Pengelolaan Desa Wisata Berbasis Masyarakat Di Desa Mas, Ubud." Jurnal Destinasi $\begin{array}{lll}\text { Pariwisata } & 7 & \text { (1): } \quad 77 .\end{array}$ https://doi.org/10.24843/jdepar.2019.v 07.i01.p12.

Juniari, Ni Wayan, and Luh Putu Mahyuni. 2020. "Implementasi Corporate Social Responsibility (CSR) Dalam Mewujudkan Pariwisata Berbasis Masyarakat Berkelanjutan." Jurnal Muara Ilmu Ekonomi Dan Bisnis 4 (1). https://doi.org/DOI:

http://dx.doi.org/10.24912/jmieb.v4i1. 7449.

Komasary, Kasih Cakaputra. 2015. "Corporate Social Responsibility Dalam Pemberdayaan Komunitas Lokal Di Destinasi Pariwisata." Bina Nusantara University.

MacRae, Graeme. 2016. "Community and Cosmopolitanism in the New Ubud." Annals of Tourism Research 59.

Mahyuni, Luh Putu. 2017. "Tantangan Pengembangan Publikasi Ilmiah Dan Pengajaran Sustainability Accounting Di Indonesia." Jurnal Ilmiah Akuntansi \& Bisnis 2 (2).

maulidiana, lina. 2018. Pengaturan CSR Menuju Pembangunan Berkelanjutan. https://doi.org/10.31227/osf.io/v8e4r.

Muhammad, Cita Insaniah, Santoso Tri Raharjo, and Risna Resnawaty. 2019. "Pelaksanaan Corporate Social Responsibility Pt. Indonesia Power Upjp Kamojang." Share : Social Work $\begin{array}{llll}\text { Journal } & 8 & \text { (2): } 195 .\end{array}$ https://doi.org/10.24198/share.v8i2.20 080 .

Nadiawati, Ni Made Yuni Sri, and I G.A.N. 
Budiasih. 2021. "Implementasi Corporate Social Responsibility Pada Hotel Puri Santrian Sanur Bali." EJur 31 (2): 451-62.

Pattisahusiwa, Salmah, and Ferry Diyanti. 2017. "Pengungkapan Corporate Social Responsibility, Struktur Corporate Governance Dan Nilai Perusahaan." Jurnal Ekonomi Modernisasi $13 \quad$ (1): 25. https://doi.org/10.21067/jem.v13i1.1 763.

Porter, Michael E, and Mark R. Kramer. 2002. "The Competitive Advantage of Corporate Philanthrophy." Harvard Business Review 80 (12): 56-68.

—. 2006. "The Link between Competitive Advantage and Corporate Social Responsibility." Harvard Business Review, 1-13.

Pribadi, Teguh Iman, Dadang Suganda, and Kurniawan Saefullah. 2021. "Pariwisata Berbasis Masyarakat Dan Dampaknya Terhadap Sosial,Ekonomi, Dan Lingkungan: Tinjauan Pustaka." Jurnal Sosial Dan Sains 1 (2).

Purwati, Desak Komang Indah, and Agus Indra Tenaya. 2018. "Implementasi Corporate Social Responsibility Berlandaskan Filosofi Tri Hita Karana Pada Lembaga Perkreditan Desa." E-Jurnal Akuntansi 23: 2203. https://doi.org/10.24843/eja.2018.v23 .i03.p22.

Rahmadani, Rahmadani, Santoso Tri Raharjo, and Risna Resnawaty. 2019. "Fungsi Corporate Social Responsibility (CSR) Dalam Pengembangan Dan Pemberdayaan Masyarakat." Share: Social Work $\begin{array}{llll}\text { Journal } \quad 8 & \text { (2): } 203 .\end{array}$ https://doi.org/10.24198/share.v8i2.2 0081.

Ratnaningsih. 2014. "Partisipasi Masyarakat Lokal Dalam Pariwisata (Studi Kasus Di Desa Wisata Belimbing, Tabanan, Bali).” Jurnal
Destinasi Pariwisata 3 (1): 45-51.

Rita, Rita. 2019. "Implementasi Corporate Social Responsibility." PUSAKA (Journal of Tourism, Hospitality, Travel and Business Event) 1 (1): 2935.

https://doi.org/10.33649/pusaka.v1i1.1 0 .

Rosilawati, Yeni, and Krisna Mulawarman. 2019. "Kearifan Lokal Tri Hita Karana Dalam Program Corporate Social Responsibility." Jurnal ASPIKOM 3 (6): 1215. https://doi.org/10.24329/aspikom.v3i6. 426.

Saldana, Johnny. 2013. The Coding Manual for Qualitative Researchers. Thousand Oaks, California: Sage Publications, Inc.

Salsabila, Tsuraya Annisa, and R. Slamet Santoso. 2018. "Analisis Stakeholders (Aktor Kebijakan) Dalam Pengembangan Obyek Wisata Candi Gedongsongo Di Kabupaten Semarang," 1-15.

Santoso, Sugeng. 2016. "Konsep Corporate Social Responsibility Dalam Perspektif Konvensional Dan Fiqh Sosial." Ahkam: Jurnal Hukum Islam 4 (1): 81-104. https://doi.org/10.21274/ahkam.2016.4 .1.81-104.

Sastrayuda, Gumelar S. 2010. "Konsep Pengembangan Kawasan Agrowisata." Hand Out Mata Kuliah Concept Resort and Leisure, Strategi Pengembangan Dan Pengelolaan Resort and Leisure.

Siwi, Mahmudi. 2017. "Kontestasi Pengetahuan Negara, Swasta Dan Masyarakat Dalam Pengelolaan Program Corporate Social Responsibility." Jurnal Sains Komunikasi Dan Pengembangan Masyarakat [JSKPM] 1 (1): 115. https://doi.org/10.29244/jskpm.1.1.115 -128 .

Soritua, Yohanes. 2016. "Analysis Of The Role Of Tourism Sector To Be The 
Jurnal Ilmiah Ekonomi dan Bísnis

Vol. 17. No.2, September 2020 : 99-105

EISSN : $2442-9813$

ISSN : $1829-9822$

Main Income In The Region (A

158

Comparation Study in the Tourism

Sector in Bali Province)." Journal of

Tourism and Hospitality

Management 4 (1): 64-75.

Sri Rokhlinasari. 2012. "Teori -Teori

Dalam Pengungkapan Informasi

Corporate Social Responbility

Perbankan" 66: 37-39.

Sudarwati, Yuliana. 2019. "Pengaruh

Pengungkapan Corporate Social

Responsibility (Csr) Terhadap Nilai

Perusahaan Dengan Profitabilitas,

Leverage Dan Ukuran Perusahaan

Sebagai Variabel Pemoderasi."

University of Muhammadiyah

Malang.

Suib, Mohammad Syaiful, and Nur

Hasanatul Faizah. 2019. "Corporate

Social Responsibility (CSR) Dalam

Isu-Isu Globalisasi Ekonomi (Studi

Tentang Sustainability CSR Di

Parawisata Pantai Duta

Probolinggo)." Amwaluna: Jurnal

Ekonomi Dan Keuangan Syariah. https://doi.org/10.29313/amwaluna.v $3 \mathrm{i} 2.4383$.

Sukma, Arida I Nyoman. 2014. Buku Ajar Pariwisata Berkelanjutan. SustainPress.

Suriany, Linda. 2008. "Penerapan Corporate Social Responsibility Dengan Konsep Community Based Tourism." Jurnal Ilmu Komunikasi 5

(1):

https://doi.org/https://doi.org/10.2400 2/jik.v5i1.216.

Wibisono, Yusuf. 2007. "Membedah Konsep \& Aplikasi CSR: Corporate Social Responsibility." In Seri Manajemen Berkelanjutan.

Wisnawa, I Made Bayu, Anak Agung Ratih Wijayanti, and Sulistyoadi Jokosaharjo. 2019. "Tourists Expectation and Perception Toward Sangeh Tourism Village." Journal of Business on Hospitality and Tourism $5 \quad$ (2): 218. https://doi.org/10.22334/jbhost.v5i2. 